Rev. Interd. em Cult. e Soc. (RICS), São Luís, v. 7, n. 1, p. 208 - 224, jan./jun. 2021

ISSN eletrônico: 2447-6498

\title{
POA turismo acessível: comunicação aumentativa e alternativa em materiais e sítios turísticos ${ }^{1}$
}

\section{POA accessible tourism: augmentative and alternative communication in materials and tourist sites}

\author{
EDUARDO CARDOSO* \\ Doutor em Design - UFRGS \\ Professor Adjunto - Universidade Federal do Rio Grande do Sul - UFRGS \\ eduardo.cardoso@ufrgs.br
}

\author{
ALESSANDRA LOPES DE OLIVEIRA CASTELINI** \\ Doutoranda em Diversidade Cultural e Inclusão Social - Feevale \\ Professora Assistente - Universidade Federal do Piauí - UFPI \\ alessandralopes@ufpi.edu.br
}

\author{
RITA BERSCH $^{* * * *}$ \\ Mestre em Design - UFRGS \\ Assistiva - Tecnologia e Educação \\ rita@assistiva.com.br \\ DAIANNE SERAFIM MARTINS ${ }^{* * * *}$ \\ Doutoranda em Design - UFRGS \\ Assistiva - Tecnologia e Educação \\ to.daianne@gmail.com
MICHELLE APELLANIS BORGES ${ }^{* * * * * *}$
Assistiva - Tecnologia e Educação \\ mixiborges@gmail.com \\ RENATA BONOTTO ${ }^{* * * * * *}$ \\ Doutora em Informática na Educação - UFRGS \\ Assistiva - Tecnologia e Educação \\ bonotto.renata@gmail.com
}

\footnotetext{
${ }^{1}$ Artigo submetido para avaliação em 19/05/2021 e aprovado em 16/06/2021.

* Pesquisa na área de Acessibilidade na Comunicação nos contextos de: educação inclusiva; mediação cultural acessível; e divulgação institucional acessível. Coordena o Grupo de Pesquisa COM Acesso - Comunicação Acessível e o Núcleo Interdisciplinar Pró-Cultura Acessível da Pró-Reitoria de Extensão da UFRGS.

** Pesquisadora na área Interdisciplinar com ênfase em Educação e Diversidade. Atua nas áreas de estudo: Formação de Docentes, Diversidade e Relações Étnico-Raciais, Recursos Tecnológicos e de apoio para inclusão e diversidade por meio da abordagem do Desenho Universal para Aprendizagem - DUA e Literatura em Multiformatos com princípios do DUA.

**** Trabalha com formação de professores para o Atendimento Educacional Especializado na área de Tecnologia Assistiva, Comunicação Alternativa, Acesso ao Computador, Recursos pedagógicos com acessibilidade.

**** Atua como Terapeuta Ocupacional e professora em cursos e formações nos seguintes temas: Tecnologia Assistiva, Comunicação Aumentativa e Alternativa, Acessibilidade, Educação Inclusiva e Desenho Universal para Aprendizagem. Integra o Grupo de Pesquisa COM Acesso - Comunicação Acessível da UFRGS.

Trabalha nas áreas de Linguagem e Fonoaudiologia Neurofuncional com pessoas com necessidades complexas de comunicação. Também atua na área de Disfagia em avaliação, diagnóstico e reabilitação à beira leito no Hospital de Clínicas de Porto Alegre.

****** Áreas de pesquisa: Tecnologia Assistiva/Comunicação Aumentativa e Alternativa, Dimensão Afetiva dos processos de ensino e aprendizagem, Educação Inclusiva e Tecnologia Educacional.
} 
Rev. Interd. em Cult. e Soc. (RICS), São Luís, v. 7, n. 1, p. 208 - 224, jan./jun. 2021

ISSN eletrônico: 2447-6498

\title{
RESUMO
}

Este artigo socializa ações do projeto de pesquisa e extensão intitulado POA Turismo Acessível, em parceria com a Universidade Federal do Rio Grande do Sul - UFRGS, Assistiva - Tecnologia e Educação, ISAAC Brasil e a Diretoria de Acessibilidade e Inclusão Social e Diretoria de Turismo de Porto Alegre, com objetivo de desenvolver projetos com emprego de Comunicação Aumentativa e Alternativa - CAA em materiais e em locais turísticos da cidade. A pesquisa qualitativa, com referencial metodológico no estudo de caso, apresenta aportes legais que respaldam a comunicação acessível, referenciais da CAA e do turismo acessível. Discutem-se premissas do Projeto e descrição do material gráfico produzido com implementação das ações em parques infantis de praças públicas da cidade. Os resultados revelaram abrangência do estudo, com evidências das ações desenvolvidas, apontando alternativas para elaboração e disseminação de placas com estratégias de CAA, ampliando discussões em prol do turismo mais acessível no Brasil.

Palavras-chave: Acessibilidade. Turismo. Comunicação Aumentativa e Alternativa.

\begin{abstract}
This article shares the actions of the research and extension project entitled POA Turismo Acessível, in partnership with the Federal University of Rio Grande do Sul - UFRGS, Assistive - Technology e Educação, ISAAC Brazil and the Accessibility and Social Inclusion Directorate and the Tourism Directorate of Porto Alegre, with the objective of developing projects using Augmentative and Alternative Communication - CAA in materials and in tourist places in the city. Qualitative research, with a methodological framework in the case study, presents legal contributions that support accessible communication, CAA references and accessible tourism. Project premises and description of the graphic material produced with the implementation of actions in playgrounds in public squares in the city are discussed. The results revealed the scope of the study, with evidence of the actions developed, pointing out alternatives for the elaboration and dissemination of signs with CAA strategies, expanding discussions in favor of more accessible tourism in Brazil.
\end{abstract}

Keywords: Accessibility. Tourism. Augmentative and Alternative Communication.

\section{INTRODUÇÃO}

A crescente urbanização da sociedade contemporânea faz com que a maioria das pessoas do mundo viva em cidades $^{2}$. Este artigo $^{3}$ busca socializar ações desenvolvidas no âmbito do Projeto intitulado POA Turismo Acessível realizados na cidade de Porto Alegre, no estado do Rio Grande do Sul, Brasil.

Cogitar uma cidade para todos requer refletir sobre o povo que a constitui, evidenciando-se o fato de sua riqueza estar na diversidade. E nessa, encontram-se, também, as

\footnotetext{
${ }^{2}$ UNICEF. Situação Mundial da Infância 2012. Disponível em: < http://www.unicef.org.br>. Acesso em: 24 out. 2020.

${ }^{3}$ Trata de uma versão alargada do resumo publicado no Livro de Resumos da INCLUDIT VI - CARDOSO, E.; CASTELINI, A. L. O.; BERSCH, R.; BONOTTO, R.; MARTINS, D. S.; PÓSTER, M. A. B. POA Turismo Acessível: Comunicação Aumentativa e Alternativa em materiais e sítios turísticos. Livro de Resumos da VI Conferência Internacional para a Inclusão 2020. Politécnico de Leiria, ESECS, CICS.NOVA.IPLeiria-iACT. \& CI\&DEI.
} 
Rev. Interd. em Cult. e Soc. (RICS), São Luís, v. 7, n. 1, p. 208 - 224, jan./jun. 2021

ISSN eletrônico: 2447-6498

pessoas com e sem deficiência, que, independente de sua identidade, de seu histórico ou de suas habilidades ${ }^{4}$, devem conviver em sociedade com igualdade de oportunidades.

E, para poderem viver em sociedade, a comunicação, enquanto um direito de todos ${ }^{5}$, é essencial. Desse modo, a fim de atender aos mais diversos públicos, deve-se exercitar a prática de comunicar em múltiplos meios e formatos, ou seja, considerando diferentes interlocutores e suas capacidades.

Pensar em múltiplos formatos é pensar em acessibilidade, uma vez que: a palavra falada pode ser sinalizada (como na Língua Brasileira de Sinais - LIBRAS); ou a imagem veiculada pode ser descrita (audiodescrição) ou mesmo ter relevo (Braille e/ou recursos táteis); ou, ainda, um vídeo pode ter legendas descritivas, considerando o público surdo que não utiliza Libras, ou mesmo idosos ou estrangeiros; ou, igualmente, qualquer um que possa utilizar-se de outro formato como apoio ou base para compreensão do que se comunica.

São muitas as possibilidades de comunicação em multiformatos e são muitos os recursos de Tecnologia Assistiva - TA que podem promover a participação de todos, incluindo as pessoas com deficiência sempre com foco na eficiência de cada indivíduo, isto é, em suas capacidades de acordo com as possibilidades que se lhe ofertam. Mais especificamente, entende-se TA enquanto área do conhecimento, de característica interdisciplinar, que engloba produtos, recursos, metodologias, estratégias, práticas e serviços, objetivando promover a funcionalidade relacionada à atividade e à participação de pessoas com deficiência, incapacidades ou mobilidade reduzida, visando à sua autonomia, independência, qualidade de vida e inclusão social ${ }^{6}$.

Algumas pessoas, por diferentes causas, apresentam uma defasagem entre sua necessidade comunicativa e sua habilidade para expressar e/ou compreender o que é dito e/ou escrito. Nesse grupo, encontram-se pessoas com deficiência física causada por paralisia cerebral, acidente vascular cerebral, trauma craniano, esclerose lateral amiotrófica; autismo, deficiência intelectual, entre outras. Nessas circunstâncias, podem-se disponibilizar recursos

\footnotetext{
${ }^{4}$ UNESCO. Resumo do Relatório de Monitoramento Global da Educação 2020: Inclusão e educação para todos. Paris, UNESCO.3RELATÓRIO DE MONITORAMENTO GLOBAL DA EDUCAÇÃO 2020. $\begin{array}{llllll}\text { RESUMOED-2020 } & \text { / } & \text { WS } & \text { / } & \text { Disponível }\end{array}$ https://unesdoc.unesco.org/ark:/48223/pf0000373721_por>Acesso em junho/2020.

5 UNESCO. Education 2030: Incheon Declaration and Framework for Action: towards inclusive and equitable quality education and lifelong learning for all. Brasília. 2016. 56p. Acedido em 15 de Jan. 2019, em http://www.unesco.org/new/pt/brasilia/about-this-office/single view/news/education_2030_incheon_declaration_and_and_framework_for_ac/

${ }^{6}$ BRASIL. Comitê de Ajudas Técnicas - CAT. Tecnologia Assistiva. Brasília: CORDE, 2009.
} 
Rev. Interd. em Cult. e Soc. (RICS), São Luís, v. 7, n. 1, p. 208 - 224, jan./jun. 2021

ISSN eletrônico: 2447-6498

de Comunicação Aumentativa e Alternativa (CAA), e isso envolve o uso integrado de símbolos (gráficos e corporais) e de recursos.

Apesar de o conhecimento e de a prática da CAA já existirem no Brasil há 40 anos, essa é uma área relativamente pouco conhecida da população em geral e poderia ajudar muitas pessoas que estão impedidas de se comunicar em diferentes contextos sociais, incluindo as áreas turísticas de lazer e de cultura.

Nesse sentido, o presente artigo apresenta a descrição de um projeto de pesquisa e de extensão intitulado POA Turismo Acessível. Trata-se de uma parceria entre a Universidade Federal do Rio Grande do Sul - UFRGS, a Assistiva - Tecnologia e Educação, a ISAAC Brasil e a Diretoria de Acessibilidade e Inclusão Social e Diretoria de Turismo de Porto Alegre, com objetivo de desenvolver projetos com o emprego de CAA em materiais e em locais turísticos da cidade de Porto Alegre, Rio Grande do Sul - Brasil.

A pesquisa segue uma abordagem qualitativa $^{7}$ e ancora-se como referencial metodológico no estudo de caso $^{8}$, o qual é adotado por se tratar de uma investigação empírica com fenômeno, pouco investigado e com exigência de aprofundamento. Fundamentados nos aportes de Yin $^{9}$, a abrangência do estudo apresentará evidências de intervenção proposta no Brasil com vistas a ampliar discussões e a descrever o projeto desenvolvido em prol do turismo acessível.

Os procedimentos metodológicos expor-se-ão em duas etapas. Na primeira, discutirse-ão os aportes legais que tratam da comunicação acessível, referenciais que respaldam a CAA e o turismo acessível, visando a contribuições para a área. Na segunda, objetiva-se identificar as premissas do desenvolvimento do Projeto POA Turismo Acessível e a descrição do material gráfico produzido e a implementação voltados a parques infantis de praças públicas da cidade de Porto Alegre.

A discussão dos resultados dar-se-á em relação à revisão bibliográfica, aos aportes legais e à socialização do projeto, apontando alternativas para a elaboração e a disseminação de placas com pranchas em CAA, contribuindo para o turismo mais acessível em parques da cidade.

\footnotetext{
${ }^{7}$ MARTINS, H.H.T.S. Metodologia Qualitativa de pesquisa. Educação e pesquisa. São Paulo, v.30, n.2 p: 289-300, maio/ago. 2004.

${ }^{8}$ STAKE, R. E. Investigación con estudio de casos. Madrid: Morata. 1999.

${ }^{9}$ YIN, R. K. Estudo de caso: planejamento e métodos. 5. ed. Porto Alegre: Bookman, 2015.
} 
Rev. Interd. em Cult. e Soc. (RICS), São Luís, v. 7, n. 1, p. 208 - 224, jan./jun. 2021

ISSN eletrônico: 2447-6498

\section{A COMUNICAÇÃO AUMENTATIVA E ALTERNATIVA}

Neste estudo, considera-se como acessível o produto, a solução ou o espaço que possibilitam a acessibilidade às pessoas sem a ocorrência de dificuldades com promoção de acesso e de deslocamento de pessoas com deficiência sem a necessidade do auxílio de outros indivíduos.

Contudo, acessibilidade não significa apenas permitir que pessoas com deficiência possam se locomover pelos espaços. Ponderar sobre acessibilidade é garantir a inclusão de todos em qualquer ambiente, atividade ou uso de recurso.

No Brasil, o Decreto $\mathrm{n}^{\circ}$ 5.296, de 2 de dezembro de $2004^{10}$, define o seguinte conceito:

Art. $8^{\circ}$ sobre a Acessibilidade: condição para utilização, com segurança e autonomia, total ou assistida, dos espaços, mobiliários e equipamentos urbanos, das edificações, dos serviços de transporte e dos dispositivos, sistemas e meios de comunicação e informação, por pessoa portadora de deficiência ou com mobilidade reduzida. (BRASIL, 2004).

Sobre as barreiras, o Decreto $n^{\circ} 5.296 / 2004$ define como

qualquer entrave ou obstáculo que limite ou impeça o acesso, a liberdade de movimento, a circulação com segurança e a possibilidade de as pessoas se comunicarem ou terem acesso à informação, classificadas em: barreiras urbanísticas, barreiras nas edificações, barreiras nos transportes e barreiras nas comunicações e informações. (BRASIL, 2004) $)^{11}$

Para Romeu Sassaki ${ }^{12}$, “[...] a inclusão social é o processo pelo qual a sociedade se adapta para poder incluir as pessoas com necessidades especiais e, simultaneamente, estas pessoas se preparam para assumir seus papéis na sociedade” (SASSAKI, 2005, p.41). Nesse sentido, pode-se afirmar que acessibilidade e a inclusão social estão diretamente ligadas. Tal informação torna-se mais efetiva ao refletir que:

Para haver efetiva inclusão social é primordial a acessibilidade, que significa a possibilidade de utilizar, com segurança e autonomia, os espaços mobiliários e equipamentos urbanos, das edificações, dos transportes e meios de comunicação, por pessoa com deficiência ou mobilidade reduzida. (CERIGNONI; RODRIGUES, 2005, p.62).

\footnotetext{
${ }^{10}$ BRASIL. Decreto n $\mathbf{n}^{\mathbf{0}} \mathbf{5 . 2 9 6}, 2$ de dezembro de 2004. Normas gerais e critérios básicos para a promoção da acessibilidade das pessoas portadoras de deficiência ou com mobilidade reduzida. Acesso em 01 set. 2020 , disponível em: http://www.planalto.gov.br/ccivil_03/_Ato2004-2006/2004/Decreto/D5296.htm.

${ }^{11}$ Idem.

${ }^{12}$ SASSAKI, Romeu K. Acessibilidade: Uma chave para a inclusão social. 05 maio 2005.Disponível em: <http://www.lainsignia.org/2004/junio/soc_003.htm>.Acesso em: abril, 2019.
} 
Rev. Interd. em Cult. e Soc. (RICS), São Luís, v. 7, n. 1, p. 208 - 224, jan./jun. 2021

ISSN eletrônico: 2447-6498

Para Schirmer ${ }^{13}$, consideram-se barreiras na comunicação e na informação quaisquer entraves ou obstáculos que dificultem ou impossibilitem a expressão ou o recebimento de mensagens por intermédio dos dispositivos, meios ou sistemas de comunicação, sejam ou não de massa, bem como aqueles que dificultem ou impossibilitem o acesso à informação.

Dessa forma, considerar acessibilidade na comunicação é condição essencial sem a qual não há inclusão. $\mathrm{O}$ ato de comunicar faz parte da natureza humana ${ }^{14}$ e somente pela comunicação o indivíduo pode exercer seu papel como cidadão e influenciar, com sua participação, o andamento e o rumo da sua história e da sociedade da qual faz parte. Ferreira, Ponte e Azevedo ${ }^{15}$ consideram que todas as pessoas, independentemente da idade ou da condição, podem utilizar meios e modos alternativos de comunicação como um meio temporário ou de longo prazo.

No Brasil, compreende-se a CAA enquanto um direito do cidadão com deficiência ${ }^{16}$ assim como um grande benefício para toda a população, pois um recurso pensado para um público específico pode beneficiar a muitos outros ao estimular novas experiências e formas de comunicação.

Bersch e Schirmer ${ }^{17}$ consideram que a CAA é destinada às pessoas de todas as idades que não apresentam fala ou escrita funcional, seja devido a algum tipo de deficiência intelectual, autismo, acidente vascular cerebral, traumatismo cranioencefálico, paralisia cerebral, entre outros. Ainda, ponderam que a introdução da CAA deve acontecer sempre que houver necessidade, aumentando, assim, as oportunidades de interação, tornando a comunicação mais acessível.

O campo da CAA diz respeito à concepção, ao desenvolvimento, à produção e à distribuição de assistência e apoios. De acordo com a associação American Speech-Language-

\footnotetext{
${ }^{13}$ SCHIRMER, C. R. Acessibilidade na comunicação é um direito - Comunicação alternativa é um caminho. Revista TEIAS: Rio de Janeiro, ano 9, nº 17, pp. 3-11, jan/jun, 2008. https://www.epublicacoes.uerj.br/index.php/revistateias/article/view/24039/17008

${ }^{14}$ MANZINI, E. J.; DELIBERATO, D. Portal de ajudas técnicas para educação: equipamento e material pedagógico especial para educação, capacitação e recreação da pessoa com deficiência física: recursos para comunicação alternativa. 2. ed. Brasília: MEC/SEESP, 2006.

${ }^{15}$ FERREIRA, M.; PONTE, M.; AZEVEDO, L. Inovação curricular: implementação de meios alternativos de comunicação em crianças com deficiência neuromotora grave. $1^{\circ}$ ed. Lisboa. Secretariado nacional para a reabilitação e integração das pessoas com deficiência, 1999.

${ }^{16}$ BRASIL. Lei $\mathrm{n}^{\circ}$ 13.146, de 6 de julho de 2015. Lei Brasileira de Inclusão da Pessoa com Deficiência. Acesso em agosto de 2020, disponível em: http://www.planalto.gov.br/ccivil_03/_Ato20152018/2015/Lei/L13146.htm

${ }^{17}$ BERSCH, R.; SCHIRMER, C. R. Comunicação aumentativa e alternativa - CAA. In: SCHIRMER, Carolina R., et al. Atendimento Educacional Especializado: Deficiência Física. São Paulo: MEC/SEESP, 2007.
} 
Rev. Interd. em Cult. e Soc. (RICS), São Luís, v. 7, n. 1, p. 208 - 224, jan./jun. 2021 ISSN eletrônico: 2447-6498

Hearing Association - ASHA ${ }^{18}$, a CAA consiste em um conjunto integrado de símbolos, recursos, técnicas e estratégias.

O Sistema Pictográfico de Comunicação - SPC consiste em símbolos que constituem unidades representacionais, podendo envolver gestos, imagens ou sons, os quais representam palavras ou mensagens. Os recursos podem ser materiais impressos, físicos ou eletrônicos, envolvendo o uso de dispositivos, como celulares, tablets e computadores (ASHA, 2004).

A partir da segunda metade da década de 70 surgiram diferentes sistemas de CAA, destacando-se os sistemas gráficos que contemplaram pessoas com deficiência motora e/ou cognitiva, entre outros, desencadeando-se na criação de novos signos gráficos, servindo, inclusive, às pessoas com dificuldade do domínio da escrita ${ }^{19}$.

Em CAA, usam-se símbolos pictográficos para representar objetos, ações, conceitos e emoções, podendo incluir desenhos, fotografias, objetos, expressões faciais, gestos, símbolos auditivos (palavras faladas) ou ortográficos (símbolos baseados no alfabeto). Segundo Sousa $^{20}$, os símbolos gráficos representam visualmente palavras ou conceitos divididos em seis categorias gramaticais: pessoas, verbos, adjetivos, substantivos, sociais e diversos.

Todavia, os símbolos em um sistema CAA devem permitir flexibilidade, pois não são universais em uma cultura. Por isso, é importante encontrar símbolos relevantes ao indivíduo e à sua comunidade/contexto. Desse modo, a seleção deles também é baseada na capacidade das pessoas de acessar, de reconhecer e de aprender o significado dos símbolos.

Beukelman e Light $^{21}$ destacam que o propósito central da CAA não é encontrar uma solução tecnológica para problemas de comunicação, mas habilitar indivíduos para, de maneira eficiente e eficaz, engajarem-se em uma gama variada de interações e participarem de atividades de sua escolha, exercendo, assim, autodeterminação.

De modo mais específico, essas interações comunicativas permitem: (1) comunicar necessidades e vontades; (2) transferir informações; (3) aproximar socialmente para

\footnotetext{
18 AMERICAN SPEECH-LANGUAGE-HEARING ASSOCIATION - ASHA. Roles and responsibilities of speech-language pathologists with respect to augmentative and alternative communication: Technical Report. ASHA Supplement 24, 2004.

${ }^{19}$ ROSELL, C.; BASIL, C. Sistemas de Signos manuales y sistemas de signos gráficos: carcateristicas e critérios para su uso. In C. B. Aumirall, E. Soro - Camats, \& C. R. Bultó (Eds.), sistemas de signos y ayudas técnicas para la comunicacion aumentativa y la escritura: princípios teóricos y aplicaciones (p.7-21). Barcelona: Masson, S.A, 1998.

${ }^{20}$ SOUSA. C. M. A. O. A. Literatura Para Todos. In: CURSO CULTURA E ACESSIBILIDADE: PESQUISA, FORMAÇÃO E PRODUÇÃO, Porto Alegre, RS, Brasil, 2017.

${ }^{21}$ BUEKELMAN, D. R.; LIGHT, J. C. Augmentative \& Alternative Communication: supporting children and adults with complex communication needs. Baltimore, Brookes, 5. ed, 2020.
} 
Rev. Interd. em Cult.e Soc. (RICS), São Luís, v. 7, n. 1, p. 208 - 224, jan./jun. 2021

ISSN eletrônico: 2447-6498

estabelecer, manter ou desenvolver engajamento social para construir relacionamentos; (4) praticar etiqueta social e (5) proporcionar organização por meio de diálogo interno (BEUKELMAN; LIGHT, 2020).

De acordo com Beukelman e Light (2020), os benefícios da CAA são: (1) aprimorar a comunicação; (2) apoiar o desenvolvimento da linguagem; (3) aumentar a participação; (4) apoiar a compreensão; (5) diminuir a frustração e os problemas de comportamento. Uma vez que a comunicação é essencial para o indivíduo exercer sua cidadania e participação na sociedade, a CAA fornece à pessoa a possibilidade de autonomia e acesso às oportunidades em condição de igualdade com seus pares.

\section{O TURISMO ACESSÍVEL}

Favorecer condições de acessibilidade é um modo de tornar a sociedade mais inclusiva, visto que ao fornecer acesso a todas as pessoas da sociedade resulta em minimizar barreiras que impedem as pessoas de ter acesso aos espaços de convivência. Entretanto, para superar essas barreiras ainda existentes, torna-se necessário um referencial legislativo a fim de garantir os direitos básicos que muitas vezes são negados.

Considera-se a Lei Brasileira $\mathrm{n}^{\circ}$ 10.098, de dezembro de 2000, mais conhecida como Lei da Acessibilidade ${ }^{22}$, a qual no artigo $1^{\circ}$ estabelece normas gerais e critérios básicos para a promoção da acessibilidade mediante a supressão de barreiras e de obstáculos nos diferentes espaços públicos, mobiliários, edificações e comunicações (BRASIL, 2000).

A referida Lei ainda salienta, no artigo $2^{\circ}$, a acessibilidade como: possibilidade e condição de alcance para utilização, com segurança e autonomia, dos espaços, dos mobiliários e dos equipamentos urbanos, das edificações, dos transportes e dos sistemas e dos meios de comunicação por pessoa portadora de deficiência ou com mobilidade reduzida. (BRASIL, 2000).

Ao compreender as normativas que determinam orientações a todos os espaços para que ofereçam acessibilidade às pessoas com deficiência com o intuito de elas conseguirem autonomia e independência, ou seja, diversas normativas, explicitando a necessidade da

\footnotetext{
${ }^{22}$ BRASIL. Lei $\mathbf{n}^{\mathbf{0}} \mathbf{1 0 . 0 9 8}$, de 19 de dezembro de 2000. Normas gerais e critérios básicos para a promoção da acessibilidade das pessoas portadoras de deficiência ou com mobilidade reduzida. Disponível em:<http://www.planalto.gov.br/ccivil_03/LEIS/L10098.htm
} 
Rev. Interd. em Cult. e Soc. (RICS), São Luís, v. 7, n. 1, p. 208 - 224, jan./jun. 2021

ISSN eletrônico: 2447-6498

eliminação de obstáculos que impedem a pessoas com deficiência de realizarem tarefas comuns. Nota-se, entretanto, o fato de essas barreiras ainda permearem os espaços e dificultarem o acesso digno desses indivíduos.

Sassaki $^{23}$ destaca que as barreiras nos espaços que dificultam a acessibilidade precisam ser desfeitas para que todos consigam ter acesso. As barreiras mencionadas pelo autor podem ser descritas como:
(1) Arquitetônica (sem barreiras físicas);
(2) Comunicacional (sem barreiras na comunicação entre pessoas);
(3) Metodológica (sem barreiras nos métodos e técnicas de lazer, trabalho, educação, etc.);
(4) Instrumental (sem barreiras instrumentos, ferramentas, utensílios, etc.);
(5) Programática (sem barreiras embutidas em políticas públicas, legislações, normas, etc.);
(6) Atitudinal (sem preconceitos, estereótipos, estigmas e discriminações nos comportamentos da sociedade para pessoas que têm deficiência); (SASSAKI, 2010, p. 67-68).

Desse modo, ao refletir sobre as diversas barreiras que impedem a pessoa com deficiência de ter acesso de forma digna aos lugares, destaca-se a relevância da promoção da acessibilidade com objetivo de atender a todos, independentemente do contexto das deficiências, considerando as especificidades e os aspectos diversos que permeiam as atividades humanas, delineada com estratégias do desenho universal a considerar todos os indivíduos que usufruem de um produto, serviço ou espaço.

O conceito de turismo, conforme a Organização Mundial do Turismo - $\mathrm{OMT}^{24}$, é expresso como "[...] o ato de visitar e conhecer lugares preconizando um tempo de permanência e atividades que as pessoas realizam durante viagens e estadas em lugares diferentes do seu entorno habitual, com finalidade de lazer, negócios e outros" (OMT, 2001, p.04).

Bull $^{25}$ afirma que o turismo é uma atividade humana que envolve movimentos e comportamentos humanos, usos de recursos, interação com outras pessoas, relações econômicas e de diferentes ambientes. Nesse sentido, convém perceber que, se há interação entre culturas e diferentes povos, torna-se importante refletir o turismo enquanto um

\footnotetext{
${ }^{23}$ SASSAKI, R. K. Inclusão: construindo uma sociedade para todos. 7.ed., Rio de Janeiro, WVA, 2010.

${ }^{24}$ ORGANIZAÇÃO MUNDIAL DE TURISMO - OMT. Introdução ao Turismo. São Paulo, Roca, 2001.

${ }^{25}$ BULL, A. The Economics os Travel and Tourism. 2 ed., Longman, 1995.
} 
Rev. Interd. em Cult. e Soc. (RICS), São Luís, v. 7, n. 1, p. 208 - 224, jan./jun. 2021

ISSN eletrônico: 2447-6498

fenômeno sociocultural, implicando em questões como direitos, exercício da cidadania e inclusão social ${ }^{26}$.

O turismo está ganhando cada vez mais espaço nas cidades, gerando empregos e contribuindo de forma satisfatória para o desenvolvimento das regiões ${ }^{27}$. Nessa perspectiva, ações governamentais são essenciais para garantir a participação de todos. De acordo com a OMT e o Ministério do Turismo - MTUR, estima-se que destinos onde há turismo acessível, consequentemente, tem um maior número de turistas.

A Associação Brasileira de Normas Técnicas - (ABNT), por meio das Normas Brasileiras - (NBR) 9050, orienta medidas para acessibilidade em edificações, mobiliários e espaços, e equipamentos urbanos. No entanto, nem sempre são cumpridas, recorrendo-se à necessidade de entidades ligadas ao turismo acessível permanecerem vigilantes para a eliminação de barreiras que impossibilitam o acesso das pessoas, sobretudo daquelas que apresentam algum tipo de deficiência.

Este estudo considera o turismo acessível como "[...] a possibilidade de viajar sozinho para qualquer lugar, sem que haja nenhum tipo de discriminação, devendo o produto turístico ser facilitado a todos, principalmente aos que possuem necessidades específicas" (PEREIRA, 2011, p.45).

No Brasil, as condições de acesso aos locais sem discriminações ou impedimentos estão presentes na legislação desde a Constituição Brasileira de 1988 (BRASIL, 1988) e na Lei N. ${ }^{\circ}$ 10.098/2000 (BRASIL, 2000), conhecida como Lei da Acessibilidade, estabelecendo que os espaços ofereçam acessibilidades para as pessoas com deficiência, eliminando obstáculos e barreiras que permeiam os espaços e dificultam o acesso. O Decreto n. 5.296/2004 (BRASIL, 2004) reafirma a acessibilidade nos espaços e garante condições para utilização total ou assistida com sistemas e meios de comunicação e de informação.

No ano de 2007, lançou-se, no Brasil, o Plano Nacional de Turismo - (PNT), voltado ao período de 2007 a 2010 (BRASIL, 2007), em que o Ministério do Turismo - MTUR acionou mecanismos de desenvolvimento econômico, tornando o Brasil um grande indutor de inclusão social.

\footnotetext{
${ }^{26}$ SILVA, H. P. DA.; COSTA, R. de K. Turismo acessível: inclusão social, acessibilidade e cidadania. Revista Turydes: Turismo y Desarrollo, n.25, 2018.

${ }^{27}$ BRASIL. Ministério do Turismo. Turismo Acessível: Introdução a uma Viagem de Inclusão. Volume I. Brasília: Ministério do Turismo, 2009. Acesso em maio de 2010, Disponível em: http://www.turismo.gov.br/turismo/o_ministerio/publicacoes/downloads_publicacoes/VOLUME_I_Introducao_a _uma_Viagem_de_Inclusao.pdf. Acesso em 01 maio de 2010
} 
Rev. Interd. em Cult. e Soc. (RICS), São Luís, v. 7, n. 1, p. 208 - 224, jan./jun. 2021 ISSN eletrônico: 2447-6498

Dentre as ações, verificou-se o apoio ao turismo acessível por meio de projetos que visam à acessibilidade urbana, adaptações de atividades turísticas, impressão de materiais de apoio, ampliando o acesso a todos. Somente em 2008, aprovou-se a Lei do Turismo N. ${ }^{\circ}$ 11.771/2008 (BRASIL, 2008), que dispõe sobre a política nacional de turismo e define as atribuições do governo federal no planejamento, desenvolvimento e estímulo ao setor turístico.

Nesse sentido, os referenciais legais apontam que "[...] a igualdade social pressupõe garantir a acessibilidade a todos, independentemente das diferenças" (BRASIL, 2009, p.09).

O MTUR apresenta em documento, elaborado em 2009, bases para o desenvolvimento do turismo acessível, destacando a importância dos seguintes elementos: preparação do destino para a acessibilidade, planejamento participativo, busca de parcerias e financiamentos, estabelecimento de estratégias de comunicação e adoção de um plano de ação (BRASIL, 2009).

Em 2015, a Lei Brasileira de Inclusão - (LBI) n. 13.146/2015 (BRASIL, 2015) tornou obrigatório a estabelecimentos de lazer e de turismo oferecer acessibilidade aos seus frequentadores.

\section{DESENVOLVIMENTO E DISCUSSÃO DOS RESULTADOS}

A primeira fase do Projeto POA Turismo Acessível compreendeu o design de material gráfico, impresso de divulgação e informação turística para rota turística, que pode ser feita caminhando em Porto Alegre, no Brasil. O mapa com o percurso turístico desenvolveu-se e aplicou-se em um folder a ser distribuído nos pontos turísticos da cidade. Devido ao acesso ao grande público, buscou-se, nesse projeto, atender ao maior número de pessoas.

A figura 1, a seguir, mostra um dos lados do folder com o mapa de orientação da rota turística em seus três percursos e pontos turísticos por meio de pictogramas. 
Rev. Interd. em Cult. e Soc. (RICS), São Luís, v. 7, n. 1, p. 208 - 224, jan./jun. 2021 ISSN eletrônico: 2447-6498

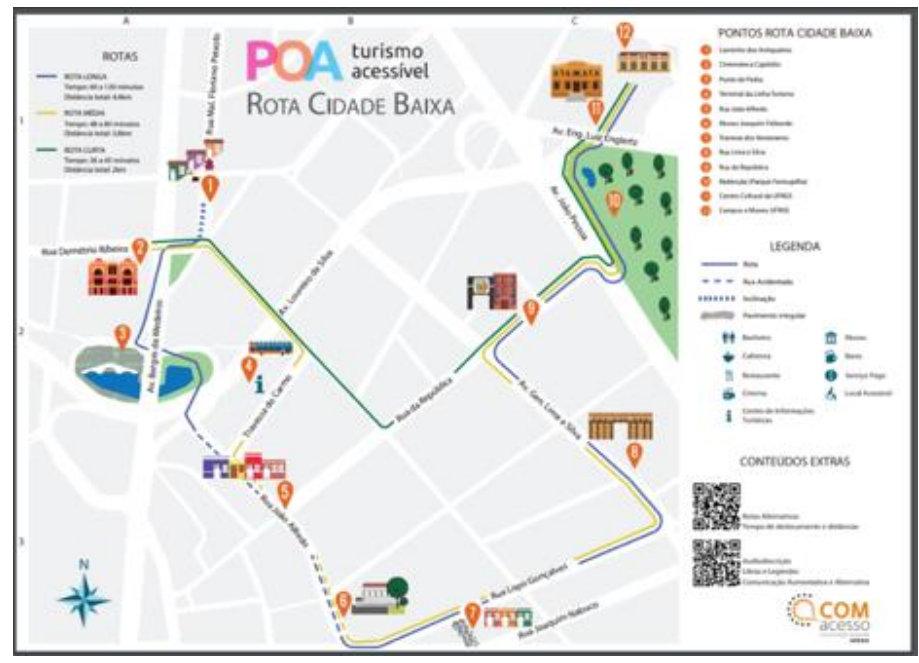

Figura 1. Folder com o Mapa Turístico - POA Acessível

Fonte: CARDOSO; CASTELINI; BERSCH; BONOTTO; MARTINS; PÓSTER (2020, p. 114).

Descrição da Imagem: Folder com o mapa turístico quadrado da Rota Cidade Baixa, em Porto Alegre no Rio Grande do Sul, Brasil. Sobre fundo branco, as quadras são desenhadas em cinza, parques em verde e as rotas em três cores, conforme sua duração: verde, amarelo e azul, da maior para a menor. Doze pontos turísticos são marcados por setas de localização e ilustrações simplificadas de suas formas. À direita, de cima para baixo, as legendas dos pontos turísticos, legendas de informações de serviço, como sanitário, acessibilidade, entre outros, e, por fim, dois QR codes com informações extras em áudio e em comunicação alternativa.

No verso do folder, há um breve texto informativo sobre os pontos turísticos, além de pictogramas universais sobre as informações de serviço de cada local. As mesmas informações foram reescritas em escrita simples e com símbolos pictográficos de comunicação (Figura 2) e podem ser acessadas por Qrcode, visto que, no folder impresso, verificam-se apenas as informações de serviço.

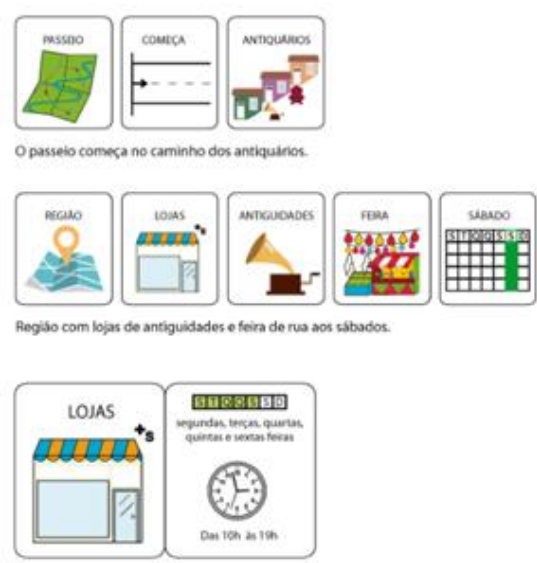

Figura 2. Texto em CAA - POA Acessível

Fonte: CARDOSO; CASTELINI; BERSCH; BONOTTO; MARTINS; PÓSTER, (2020, p. 115).

Descrição da Imagem: Texto em comunicação alternativa com a utilização de pictogramas dispostos em quadros em três linhas. Dentro do quadrado, acima de cada figura, uma palavra. E, abaixo de cada linha de quadrados, o texto por extenso. Nessa peça, tem-se a seguinte mensagem: Na primeira linha: "O passeio começa no caminho dos antiquários"; na segunda linha, "região com lojas de antiguidades e feira de rua aos sábados"; e na terceira linha, "as lojas abrem durante a semana das $10 \mathrm{~h}$ às $15 \mathrm{~h}$ ". 
Rev. Interd. em Cult. e Soc. (RICS), São Luís, v. 7, n. 1, p. 208 - 224, jan./jun. 2021

ISSN eletrônico: 2447-6498

Para a escrita com símbolos, utilizou-se a base de dados do Portal Aragonés de la Comunicación Aumentativa y Alternativa (Portal ARASAAC; http://www.arasaac.org/), assim como novos símbolos desenvolveram-se para os dez pontos turísticos da rota turística a partir dos princípios de simplicidade visual, relevância formal (identificação de elementos marcantes para o desenho de cada pictograma), alto contraste e legibilidade para aplicação em diferentes formatos e tamanhos.

A partir do trabalho inicial com o material gráfico informativo, partiu-se para a segunda fase do projeto com a aplicação da CAA em placa de comunicação em parquinhos infantis de praças da cidade.

Para o projeto piloto, indicou-se, pela prefeitura de Porto Alegre, um dos pontos turísticos mais emblemáticos da cidade, ou melhor, a Praça Júlio Mesquita, em frente à Usina do Gasômetro, conforme exposto na figura 3 a seguir.
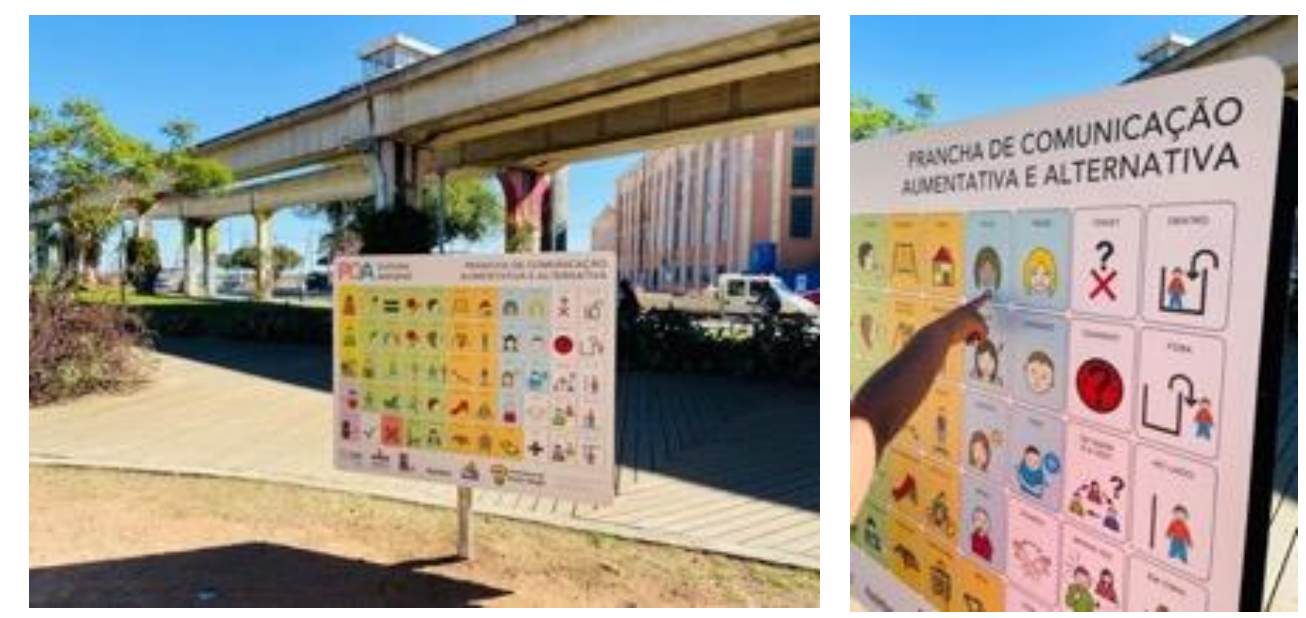

Figura 3. Implantação da Placa com prancha de CAA na Praça Júlio Mesquita

Fonte: CARDOSO; CASTELINI; BERSCH; BONOTTO; MARTINS; PÓSTER, (2020, p. 115).

Descrição da Imagem: Duas fotografias coloridas lado a lado. À esquerda, a implantação da placa em metal adesivada com as informações em comunicação alternativa em uma praça da cidade. A placa tem fundo branco e pictogramas coloridos dispostos em quadrados em dez colunas e cinco linhas, que se dividem por cor, no fundo de cada quadrado, conforme classificação de uso, isto é, em amarelo, verde, rosa, laranja, azul e branco. No topo, à esquerda, o logo POA Turismo Acessível e, à direita, o texto: prancha de comunicação aumentativa e alternativa. À direita, imagem em detalhe da foto anterior. Uma pessoa aponta para um dos símbolos em pictogramas.

A CAA empregou-se em uma placa para interação em parquinho infantil. A placa tem $1,50 \mathrm{~m}$ x 1,20m, duas faces e um tubo central para fixação no solo. Conta com a prancha de comunicação alternativa em um dos lados e no outro, com orientações gerais e um convite para se divertir ao se comunicar com a prancha (Figura 3).

Os pictogramas também se redesenham a partir da base de dados do Portal ARASAAC e reúnem um vocabulário de 55 símbolos selecionados por uma equipe de 
Rev. Interd. em Cult. e Soc. (RICS), São Luís, v. 7, n. 1, p. 208 - 224, jan./jun. 2021

ISSN eletrônico: 2447-6498

profissionais das áreas de design, terapia ocupacional, linguística, fonoaudiologia e fisioterapia.

Os símbolos organizam-se em: pronomes, saudações, ações, locais e brinquedos, sensações e estados emocionais, indicação espacial, perguntas e respostas. Dessa forma, buscam contemplar a maior parte de interações que podem acontecer no parquinho infantil.

\section{CONSIDERAÇÕES FINAIS}

Diante do exposto, compreender o turismo acessível como um processo de inclusão para todas as pessoas engloba diversas dimensões, fortalecendo a convivência com a diversidade humana, favorecendo a construção de novas relações e experiências, auxiliando no rompimento de barreiras, transformando espaços das cidades, conscientizando as pessoas para a construção de uma sociedade mais justa e equânime.

Nos estudos de Nunes e Madureira ${ }^{28}$, evidencia-se a urgência em se pensar em recursos, em práticas pedagógicas e em intervenções mais inclusivas de modo a garantir o acesso, a participação e aprendizagem de todos.

Nessa perspectiva, a utilização dos folhetos acessíveis torna-se aliado em potencial do trabalho colaborativo ao favorecer a comunicação acessível ${ }^{29}$ nos espaços culturais e educativos como forma de responder à diversidade das necessidades e das potencialidades de todos, oportunizando participação nos processos de aprendizagem e na vida em comunidade.

Nesse sentido, os dados evidenciam os processos de promoção da inclusão por meio da preocupação com a ampliação da acessibilidade nos espaços educativos e culturais com a formação de equipes de trabalhos e de pesquisas cada vez mais interdisciplinares.

Deville (2009) ${ }^{30}$ afirma que o turismo acessível tem a capacidade de reconhecer que todas as pessoas podem usufruir de equipamentos e de serviços, oferecendo satisfação e qualidade, tornando-se específico com as necessidades e as exigências que cada um possui.

\footnotetext{
${ }^{28}$ NUNES, C.; MADUREIRA, I. Desenho Universal para a Aprendizagem: Construindo práticas pedagógicas inclusivas. Revista Da Investigação às Práticas, 5 (2), 126-143, 2015.

${ }^{29}$ CASTELINI. A. L. O.;SOUSA, C. M. A. O. A.;VICENTE, L. R. Comunicação Acessível nas Grutas da Moeda. In: EBOOK VIII Conferência Internacional Investigação, Práticas e Contextos em Educação (2019). V.01 ed. Leiria - Portugal: Escola Superior de Educação e Ciências Sociais - Politécnico de Leiria, 2019. v.02. p.428 - 432. https://sites.ipleiria.pt/ipce2019/files/2019/10/Livro2_IPCE2019.pdf

${ }^{30}$ DEVILLE, E. L. O desenvolvimento do Turismo Acessível: dos argumentos sociais aos argumentos de mercado. Revista Turismo e Desenvolvimento, Portugal. v.11, 39-46, 2009.
} 
Rev. Interd. em Cult. e Soc. (RICS), São Luís, v. 7, n. 1, p. 208 - 224, jan./jun. 2021 ISSN eletrônico: 2447-6498

Levando em conta que as práticas inclusivas devem ser aplicadas em diversos contextos, o turismo acessível implica muito mais que adaptações arquitetônicas, haja vista os ambientes, equipamentos, recursos de comunicação deverem ser pensados de forma a atender a todos, considerando a diversidade existente desse público.

Dessa maneira, compreende-se que "[...] o turismo passou a ser um bem social de primeira necessidade, devendo ser acessível a todos, exigindo que os espaços turísticos forneçam condições adequadas de acessibilidade, investindo na formação dos profissionais e na diferenciação dos serviços prestados" (DEVILLE, 2009, p.38).

Em tempo, considera-se que este estudo não esgota as questões abordadas, uma vez que a inserção desse tema em debate possibilita a ampliação de produção e de adoção de produtos e de serviços turísticos cada vez mais inclusivos e que possam, de fato, chegar a um número maior de pessoas com segurança, garantindo-lhes os direitos de acessibilidade no turismo para todos os cidadãos.

Os direitos de cidadania convivem em sintonia com direitos ao lazer, à comunicação, ao ir e ao vir; por isso mesmo, não se deve esquecer da questão da acessibilidade livre de discriminação, visando à eliminação de barreiras físicas, arquitetônicas, ou até empecilhos comunicativos que possam, de alguma maneira, dificultar ou impedir que as pessoas com deficiência usufruam dos produtos e dos serviços turísticos.

O estudo pressupõe que transformar os espaços públicos, como parques infantis e atividades turísticas, para bem atender a todas as pessoas não é tarefa fácil, mas faz-se necessário. Fomentar projetos e ações que consideram o turismo acessível, multiplicando formas de acessibilidade nos espaços públicos, pressupõe modificações e ajustes necessários, assegurando que as pessoas possam ter igualdade de oportunidades em conformidade com a legislação vigente, inserindo nas políticas de turismo a necessidade de acessibilidade, promoção da inclusão social e comunicação acessível nos espaços públicos, atrativos e serviços turísticos nas cidades.

\section{REFERÊNCIAS}

AMERICAN SPEECH-LANGUAGE-HEARING ASSOCIATION - ASHA. Roles and responsibilities of speech-language pathologists with respect to augmentative and alternative communication: Technical Report. ASHA Supplement 24, 2004. 
Rev. Interd. em Cult. e Soc. (RICS), São Luís, v. 7, n. 1, p. 208 - 224, jan./jun. 2021 ISSN eletrônico: 2447-6498

BERSCH, R.; SCHIRMER, C. R. Comunicação Aumentativa e Alternativa - CAA. In: SCHIRMER, Carolina R., et al. Atendimento Educacional Especializado: Deficiência Física. São Paulo, MEC/SEESP, 2007.

BRASIL. Constituição da República Federativa do Brasil. 1988. Brasília: Senado Federal, Centro Gráfico, 1988.

BRASIL. Decreto $\mathrm{n}^{\circ}$ 5.296, 2 de dezembro de 2004. Normas gerais e critérios básicos para a promoção da acessibilidade das pessoas portadoras de deficiência ou com mobilidade reduzida. 2020. Disponível em: http://www.planalto.gov.br/ccivil_03/_Ato20042006/2004/Decreto/D5296.htm. Acesso 02 set.

BRASIL. Lei $\mathrm{n}^{\circ} 10.098$, de 19 de dezembro de 2000. Normas gerais e critérios básicos para a promoção da acessibilidade das pessoas portadoras de deficiência ou com mobilidade reduzida. Disponível em:<http://www.planalto.gov.br/ccivil_03/LEIS/L10098.htm. Acesso em 01 de jun. 2021.

BRASIL. Ministério do Turismo. Turismo Acessível: Introdução a uma Viagem de Inclusão. Volume I. Brasília: Ministério do Turismo, 2009. Disponível em:

http://www.turismo.gov.br/turismo/o_ministerio/publicacoes/downloads_publicacoes/VOLU ME_I_Introducao_a_uma_Viagem_de_Inclusao.pdf

BRASIL. Comitê de Ajudas Técnicas - CAT. Tecnologia Assistiva. Brasília, CORDE.

BRASIL. Lei no 13.146, de 6 de julho de 2015. Lei Brasileira de Inclusão da Pessoa com Deficiência. Acesso em agosto de 2020. Disponível em:

http://www.planalto.gov.br/ccivil_03/_Ato2015-2018/2015/Lei/L13146.htm

BULL, A. The Economics os Travel and Tourism. 2 ed., Longman, 1995.

BUEKELMAN, D. R.; LIGHT, J. C. Augmentative \& Alternative Communication: supporting children and adults with complex communication needs. 5. ed. Baltimore: Brookes, 2020.

CASTELINI. A. L. O.; SOUSA, C. M. A. O. A.; VICENTE, L. R. Comunicação Acessível nas Grutas da Moeda In: EBOOK VIII Conferência Internacional Investigação, Práticas e Contextos em Educação (2019). V.01 ed. Leiria - Portugal: Escola Superior de Educação e Ciências Sociais - Politécnico de Leiria, 2019. v.02. p.428 - 432. Disponível em: https://sites.ipleiria.pt/ipce2019/files/2019/10/Livro2_IPCE2019.pdf

CARDOSO, E.; CASTELINI, A. L. O.; BERSCH, R.; BONOTTO, R.; MARTINS, D. S.; PÓSTER, M. A. B. POA Turismo Acessível: Comunicação Aumentativa e Alternativa em materiais e sítios turísticos. Livro de Resumos da VI Conferência Internacional para a Inclusão 2020. Politécnico de Leiria, ESECS, CICS.NOVA. IPLeiria-iACT. \& CI\&DEI.

CERIGNONI, F. N.; RODRIGUES, M. P. Deficiência: uma questão política? São Paulo, Paulus, 2005.

DEVILLE, E. L. O desenvolvimento do Turismo Acessível: dos argumentos sociais aos argumentos de mercado. Revista Turismo e Desenvolvimento, Portugal. v.11, 39-46, 2009.

FERREIRA, M.; PONTE, M.; AZEVEDO, L. Inovação curricular: implementação de meios alternativos de comunicação em crianças com deficiência neuromotora grave. $1^{\circ}$ edição. Lisboa. Secretariado nacional para a reabilitação e integração das pessoas com deficiência, 1999.

FUNDO DAS NAÇÕES UNIDAS PARA A INFÂNCIA - UNICEF. Crianças em um mundo urbano. New York: Unicef, 2012. 
Rev. Interd. em Cult. e Soc. (RICS), São Luís, v. 7, n. 1, p. 208 - 224, jan./jun. 2021 ISSN eletrônico: 2447-6498

MARTINS, H.H.T.S. Metodologia Qualitativa de pesquisa. Educação e pesquisa. São Paulo, v.30, n.2 p: 289-300, maio/ago. 2004.

MANZINI, E. J.; DELIBERATO, D. Portal de ajudas técnicas para educação: equipamento e material pedagógico especial para educação, capacitação e recreação da pessoa com deficiência física: recursos para comunicação alternativa. 2 ed. Brasília, MEC/SEESP, 2006.

NUNES, C.; MADUREIRA, I. Desenho Universal para a Aprendizagem: Construindo práticas pedagógicas inclusivas. Revista Da Investigação às Práticas, 5 (2), 126-143, 2015. ORGANIZAÇÃO MUNDIAL DE TURISMO - OMT. Introdução ao Turismo. São Paulo: Roca, 2001.

SILVA, H. P. DA.; COSTA, R. DE K. Turismo acessível: inclusão social, acessibilidade e cidadania. Revista Turydes: Turismo y Desarrollo, n.25, 2018.

PEREIRA. M. A. M. P. Turismo acessível para todos: o caso específico de Fátima. Dissertação (Mestrado) Gestão de Organizações Turísticas na Universidade do Algarve. Leiria, Portugal, 2011.

ROSELL, C.; BASIL, C. Sistemas de Signos manuales y sistemas de signos gráficos: carcateristicas e critérios para su uso. In C. B. Aumirall, E. Soro-Camats, \& C. R. Bultó (Eds.), sistemas de signos y ayudas técnicas para la comunicacion aumentativa y la escritura: princípios teóricos y aplicaciones (p.7-21). Barcelona, Masson, S.A, 1998.

SASSAKI, Romeu K. Acessibilidade: Uma chave para a inclusão social. 05 mai. 2005.Disponível em: <http://www.lainsignia.org/2004/junio/soc_003.htm>.Acesso em: 05 abr. 2019.

SASSAKI, R. K. Inclusão: construindo uma sociedade para todos. 7.ed., Rio de Janeiro: WVA, 2010.

SCHIRMER, C. R. Acessibilidade na comunicação é um direito - Comunicação alternativa é um caminho. Revista TEIAS: Rio de Janeiro, ano 9, nº 17, pp. 3-11, jan/junho, 2008.

Disponível em: https://www.epublicacoes.uerj.br/index.php/revistateias/article/view/24039/17008

SOUSA. C. M. A. O. A. Literatura Para Todos. In: Curso Cultura e Acessibilidade: Pesquisa, Formação E Produção. Porto Alegre, RS, Brasil, 2017.

STAKE, R. E. Investigación con estudio de casos. Madrid, Morata. 1999.

UNICEF. Situação Mundial da Infância 2012. Disponível em: < http://www.unicef.org.br>. Acesso em: 24 out. 2020.

UNESCO. Education 2030. Incheon Declaration and Framework for Action: towards inclusive and equitable quality education and lifelong learning for all. Brasília. 2016. 56p. Acedido em 15 de Janeiro, 2019, em http://www.unesco.org/new/pt/brasilia/about-thisoffice/single view/news/education_2030_incheon_declaration_and_and_framework_for_ac/

UNESCO. Resumo do Relatório de Monitoramento Global da Educação 2020: Inclusão e educação para todos. Paris, UNESCO. RELATÓRIO DE MONITORAMENTO GLOBAL DA EDUCAÇÃO 2020. RESUMOED-2020 / WS / 18. Disponível em: https://unesdoc.unesco.org/ark:/48223/pf0000373721_por>Acesso em junho/2020.

YIN, R. K. Estudo de caso: planejamento e métodos. 5. ed. Porto Alegre, Bookman, 2015. 